\title{
Sierra Pérez, J. (2014). Fray José de Barcelona (1739-1800). “Dos maestros de capilla". Villancico a 10, con violines, al Santo Nacimiento. Madrid: Alpuerto, 50 pp. ISBN: 978-84-381-0486-6
}

Vide, ut quod ore cantas, corde credas; et quod corde credis, operibus comprobes

Como debe ser, máxime de manos de un especialista de larga trayectoria en el tema, como el Dr. José Sierra, se ha editado este estupendo villancico, útil, muy particularmente, por su cualidad de modélico. Trata de las entonces — para fines del siglo XVIII - ya viejas disputas (aunque entonces acaso con mayor vigencia que con anterioridad) entre lo antiguo y lo moderno. Y remeda, cantando, el enfrentamiento entre dos maestros de capilla - consecuentemente, uno "antiguo" y otro "moderno"-, que, defienden y argumentan cada uno las bondades de su postura, en detrimento de la contraria, aunque acabarán concertados en un previsible final feliz.

Nada mejor, por tanto, que poder comprobar, de primera mano, las inquietudes compositivas y estilísticas de aquel momento, de boca de sus propios protagonistas. Pero, también como debe ser, el estudio que precede a la edición en notación actual y disposición de partitura, se ha complementado en formato audio con la grabación independiente, aunque paralela, del villancico citado, que podrá ser escuchado por cualquier interesado (Real Monasterio de Guadalupe, Maestros de capilla del s. XVIII, Capilla Real de Madrid, Dir. Óscar Gershensohn. A \& B Máster Record 95-I, DDD, con selección, coordinación e investigación musicológica, asimismo a cargo de José Sierra). El disco, que contara con el apoyo del propio Real Monasterio de Guadalupe y de la Junta de Extremadura, recoge obras de Domingo de Santiago (1707-1757) —una Cantada a san Jerónimo del año 1752-, de Manuel del Pilar (1716-1794) —un Magnificat del año 1762 y un Stabat Mater-, y del propio José de Barcelona (1739-1800), entre las cuales se cuenta una Lamentación primera del Jueves del año 1777 y el mencionado villancico de los Dos maestros de capilla que aquí se reseña. Música llevada del archivo al concierto, es decir, a su fin último: sonar, ser escuchada, y que, además, se facilita aquí y ahora que pueda ser estudiada y aprehendida.

La edición en partitura aúna, como también en su trayectoria el musicólogo que protagoniza el estudio, los dos centros jerónimos de producción musical más destacados del esplendor monástico hispano de tiempos pasados: El Escorial (en torno a la figura del padre Soler) y Guadalupe (con la musicalización a cargo del padre José de Barcelona que 
protagoniza la publicación). Ambos compositores pusieron música al mismo texto, síntoma de su interés y plena vigencia durante la segunda mitad del Setecientos, en lo que acaba suponiendo ya un villancico-cantata —aludiendo al estudio clásico de Vicente Ripollés-, provisto de Introducción, Estribillo, Recitados, Arias, Motete y una "canción amorosa" final. La temática aborda la larga discusión mantenida en la época entre dos estilos, uno antiguo y otro moderno, y la evolución a que se vieron ambos sometidos, condenados a entenderse, en un contexto señoreado por la música escénica y teatral —en ascenso en toda Europa- e inmerso en un magma de óperas y zarzuelas, o de comedias armónicas más locales, que debatían la licitud de la inclusión o no, en el templo, de obras destinadas a una representación, más o menos abierta, más o menos prudente o encubierta, en un ámbito en el que oratorios y autos sacramentales se abrieron paso, no sin falta de voces encontradas. Música y teología, ortodoxia y religión...

Fuera del análisis de la documentación archivística conservada, sopesada con la prudencia y minuciosidad propias de un scriptorium medieval por José Sierra, poco se sabe del compositor, acaso barcelonés, tal vez José Riquer o Roquer, tal vez José Ferriol, que comenzara su formación musical como escolán de la Abadía de Montserrat, bajo el magisterio de José Martí a partir de 1753. Tomó el hábito en 1760 en Guadalupe, siendo entonces maestro de capilla en aquel cenobio extremeño fray Manuel del Pilar (con quien tal vez llegara a alternar el primer atril guadalupano en 1778-1781). Ascendió al magisterio musical de aquel monasterio en 1777 , puesto que desempeñó hasta 1794 , si bien data sus composiciones músicas ya desde 1773 (ochenta y tres composiciones en total en el convento extremeño, buena parte de ellas bajo advocación mariana, las cuales suelen reunir ocho voces junto a una orquesta clásica). El caso es que se le atribuye el tratado De arithmetica et algebra et musica speculativa, que se sabe que formó parte de algunos tribunales de oposiciones, y que llegó a ser elegido mayordomo mayor del monasterio guadalupano en 1785-1788. Meros datos de una trayectoria local, seguramente abnegadamente dedicada al estudio y la oración.

La partitura se anota para Tiple, Alto, Tenor y Bajo (duplicados en sendos coros, o a ocho, en ocasiones), más el preceptivo acompañamiento, que en la versión del Dr. Sierra deja su pauta superior en blanco, para que el usuario correspondiente pueda anotar, llegado el caso, la realización que gustare.

De los dos personajes protagonistas suplementarios (que suman así las diez partes vocales del tutti), el "maestro de capilla moderno" cubre una voz de Alto, mientras que el "maestro de capilla antiguo" abarca un ámbito de Bajo vocal. La sección de la cuerda se reduce a violín primero y segundo, generalmente anotados en terceras o sextas, en una escritura que comienza a ser idiomática, trabándose con el acompañamiento a modo de trío instrumental barroco, y que alterna con o se une al bloque vocal, según interesa.

El protagonista por tanto es la voz, el mensaje textual que se transmite, sin dejar paso al empleo de otro tipo de instrumentos (oboes, trompas), ya plenamente usados en la época tanto en el lugar al que esta composición se destinara, como por el propio compositor. 
El trasfondo de viejas disputas y "controversias" (la célebre de Francisco Valls, otro catalán siempre presente — como los citados Antonio Soler y fray J. de Barcelona-, y como tantos otros músicos catalanes activos en el ámbito de la corte y la catedral primada a lo largo del siglo XVIII —José Martí, José Mir y Llusá, José Elías, Francisco Juncá, Joan Rossell, Jaime Casellas, Anselmo Viola...-), nos retrotrae a la polémica del momento entre la permanencia, pervivencia o incluso preeminencia de la siempre valorada (aunque ya por entonces en cierto modo agotada) tradicional música contrapuntística, concebida en estilo severo, seguidora férrea de las normas de la armonía y la ortodoxia en la composición, tan apta para su cultivo en el templo, y el ascenso imparable y la novedad del denominado "italianismo" o música a la moda —el "género libre" —, que se imponía ya desde hacía algún tiempo como una realidad social a través de las salas de ópera, los teatros y las cortes de toda Europa.

Lucha, pues, entre lo viejo (la dictadura de las normas y leyes de la armonía), y lo nuevo (una libertad de creación apenas limitada por aquello que no ofendiera al oído y los sentidos), e incluso, una lucha, de dos posicionamientos también agotados por el mismo uso, es decir, una lucha ya antigua, que comenzaba a cansar a públicos y audiencias, y que, por tanto, se debatía por encontrar una salida airosa a través de otras formas artísticas, todavía por llegar. La composición de este villancico, su texto y su música, dan testimonio de todo ello, de aquel agotamiento temático y formal, y lo hace además con un cierto tono humorístico —entre lo socarrón y lo cándido y amable—, con vistas a ganarse a partidarios de una y otra postura, desde una perspectiva "galante", muy propia de la época, o de elegante concordia, y políticamente correcta, como diríase hoy. Una visión, la que se nos facilita, que nos permite mirar a través de la cerradura, y contemplar una escena de pelucas empolvadas, casacas con encajes y rapé, mientras personajes cortesanos admiran, halagados, entretenidos y con displicencia, viejas cuestiones de púlpito o altar e importantes disputas técnicas entre músicos, convertidas casi en fruslerías para terceros - para todos aquellos ajenos al gremio-, para finalizar todo ello con un predecible y benévolo "happy end".

La bondad de la presente propuesta editorial queda, pues, refrendada por el tino en la elección de una composición, paradigmática de un entorno musical e intelectualmente candente en la época. La obra, servirá como modelo objeto de estudio tanto para profesores como para estudiantes de música y musicología, así como, en general, como reveladora ilustración - breve, eficaz - para cualquier interesado en conocer el contexto histórico, religioso y socio-político de la España del siglo XVIII. Aproxima a un tipo de música no particularmente conocida — no al menos por el gran público-, conventual, y aporta la posibilidad del cotejo de lo anónimo español (un monje entre un millón de los posibles, que trabaja "ad maiorem Dei gloriam" — sin que parezca importarle demasiado por tanto dejar constancia de su nombre secular-, salido de un relevante aunque recóndito monasterio extremeño, a pesar de que ciertamente perteneciente a la orden acaso de mayor esplendor y raza española, como fueron los jerónimos), cotejo, digo, de lo anónimo o de escasa relevancia nominal, frente a lo más granado de la producción internacional (otro monje, también jerónimo, pero de nombre archiconocido como es el caso del padre Antonio Soler, activo en un Escorial áulico, músico en las jornadas de la realeza borbónica 


\section{RESEÑAS DE LIBROS}

en tantísimas ocasiones, discípulo del gran Domenico Scarlatti, y maestro "inter pares" junto a algunos de los mejores músicos a nivel internacional del momento).

El eje que guía la edición, la, tal vez, mayor inquietud del pensamiento musical entre los compositores del orbe hispánico del setecientos. Y por consiguiente, el meollo de la cuestión, que sirve aquí para tratar de entender una música, ya muy lejana en el tiempo, pero aún hoy, muy capaz de espolear a todas aquellas conciencias que se hallen dispuestas a abrirse al estudio del pasado, con vistas a proyectar, siquiera sea una mínima parte de aquellas sensibilidades artísticas, ideológicas y culturales — de lo que de bueno pudieran haber tenido-, a la construcción de una disciplina, la musicológica, y de una sociedad, actuales, que buscan referentes en los que poderse apoyar para avanzar en un camino que ofrezca, cuando menos, esperanza y atisbos de mejora, a las generaciones por venir.

Un gran acierto sin duda, y un trabajo, que desde la conciencia de su pequeñez, ofrecerá, a quien lo quiera buscar, mucho más de lo que aparentemente pudiera parecer. Si ama usted la música y le interesa conocer el pasado español, no se lo debería perder. Piensa globalmente, actúa localmente. Cum laude.

Antonio Ezquerro Esteban

DCH-Musicología, IMF-CSIC, Barcelona

ORCID iD: http://orcid.org/0000-0001-7289-059X 